Research Paper

\title{
The Importance of Needle Echogenity in Ultrasound Guided Axillary Brachial Plexus Block: A Randomized Controlled Clinical Study
}

Cevdet DUGER ${ }^{1 凶}{ }^{\bowtie}$, Ahmet Cemil ISBIR ${ }^{1}$, Kenan KAYGUSUZ ${ }^{1}$, Iclal OZDEMIR KOL ${ }^{1}$, Sinan GURSOY1, Hayati OZTURK², Caner MIMAROĞLU1

1. Department of Anesthesiology, Cumhuriyet University, School of Medicine, Sivas, TURKEY

2. Department of Orthopedics, Cumhuriyet University, School of Medicine, Sivas, TURKEY

$\triangle$ Corresponding author: Dr. Cevdet DUGER, Department of Anesthesiology, Cumhuriyet University, School of Medicine, 58140, Sivas, TURKEY, cevdetduger@gmail.com, Tel: 00903462580125 Fax: 00903462581305

(c) Ivyspring International Publisher. This is an open-access article distributed under the terms of the Creative Commons License (http://creativecommons.org/ licenses/by-nc-nd/3.0/). Reproduction is permitted for personal, noncommercial use, provided that the article is in whole, unmodified, and properly cited.

Received: 2013.05.02; Accepted: 2013.06.18; Published: 2013.07.04

\begin{abstract}
Objective: In this study we aimed to compare the echogenic needles and the nerve stimulation addition to non-echogenic needles in ultrasound guided axillary brachial plexus block for upper extremity surgery.

Methods: 90 patients were enrolled to the study. The patients were allocated into three groups randomly: Group E $(n=30)$ : ultrasound guided axillary block using echogenic needle, Group $N$ $(n=30)$ : ultrasound guided axillary block using non-echogenic needle, Group NS $(n=30)$ : ultrasound guided axillary block using non-echogenic needle with nerve stimulator assistance. Duration of block procedure, mean arterial pressure, heart rate, pulse-oximetry, onset time of sensory and motor block, duration of sensory and motor block, time to first analgesic use, total need for analgesics, postoperative pain scores, patient and surgeon satisfaction scores were recorded.

Results: Duration of block procedure values were lower in group $E$ and NS, sensory and motor block durations, were significantly lower in group N. Sensorial and motor block onset time values were found lower in group NS but higher in group N. Patient and surgeon satisfaction scores were found lower in group $\mathrm{N}$.

Conclusion: We conclude that ultrasound guided axillary block may be performed successfully using both echogenic needles and nerve stimulation assisted non-echogenic needles.
\end{abstract}

Key words: ultrasound, nerve stimulator, echogenity, needle, axillary nerve blockade

\section{Introduction}

Axillary brachial plexus block is a common regional anesthesia and peripheral nerve block technique in upper extremity surgery. It is very important to localize the nerve that shall be blocked and there are several ways to find the position of the nerves. Generally, these methods are four major techniques named as sensation of paresthesia, anatomical landmarks, nerve stimulation and at last ultrasonography (1-6).
Previously, ultrasound has been used to guide catheter placement and needle insertion in only radiology area, but now it is used commonly in nerve block for regional anesthesia by anesthesiologists. Ultrasound helps identification of the target tissue, nerve, vessel and other structures so that needle placement can be made accurately and safely $(4,5)$.

Innovation in ultrasound technology aims to improve the visualization of tissues and needle. These 
innovations include both ultrasound technology and needle visualization. Ultrasound guided regional anesthesia with conventional block needles may be difficult due to conventional needle tips are non-echogenic. Owing to technological improvements of needle visualization new echogenic needles are started to be used in clinical practice $(3,5,6)$. Despite some studies comparing echogenic and non-echogenic needles, according to our review of literature it could not be found any study which compares echogenic, non-echogenic needles and nerve stimulator assistance together in a clinical study on the basis of operation outcomes such as block quality, performing time, pain and satisfaction scores.

In this study we aimed to compare outcomes of the echogenic needles and non-echogenic needles with nerve stimulation addition in ultrasound guided axillary brachial plexus block for upper extremity surgery.

\section{MATERIALS AND METHODS}

This randomized controlled clinical study was performed after the approval of the ethical committee (Number: 2011-04/15) and written informed consent of the patients. In this study, 90 ASA physical status I-II patients scheduled for upper extremity surgery under axillary nerve block were enrolled. Patients with a history of coagulopathy, local anesthetic allergy, respiratory failure, cardiac disease, hepatic failure, or renal failure, receiving chronic analgesic therapy, obesity (Body mass index > 27) and pregnancy were exclusion criteria for the study. The patients were allocated into three groups randomly: Group E ( $\mathrm{n}=$ 30): ultrasound guided axillary block with echogenic needle, Group N ( $\mathrm{n}=30)$ : ultrasound guided axillary block with non-echogenic needle, Group NS $(n=30)$ : ultrasound guided axillary block with non-echogenic needle using nerve stimulator assistance. The randomization was achieved by a random number table and the patients were not informed about their groups.

Patients were not given any premedication before the operation. Just before the block procedure mean arterial blood pressures (MAP), heart rate (HR), and peripheral oxygen saturation $\left(\mathrm{SpO}_{2}\right)$ monitoring were performed and baseline values were recorded. Axillary block was performed while the patient in the supine position, the elbow with $110^{\circ}$ flexion and the upper arm with $90^{\circ}$ abduction. All block procedure was performed using the same ultrasound (eZono ${ }^{\mathrm{TM}}$ 3000 portable ultrasound, Germany) device with a 4 $\mathrm{cm}$ probe and frequency of 6-10 MHz (eZono ${ }^{\mathrm{TM}}$ Linear Probe, Germany). Group E patients were blocked using an echogenic 22G, $50 \mathrm{~mm}$ stimulating needle
(Stimuplex Ultra, B.Braun Melsungen AG) with the guidance of only ultrasound device, group $\mathrm{N}$ patients were blocked using a non-echogenic $22 \mathrm{G}, 50 \mathrm{~mm}$ stimulating needle (Stimuplex A, B.Braun Melsungen AG) with the guidance of only ultrasound device, group NS patients were blocked using non-echogenic $22 \mathrm{G}, 50 \mathrm{~mm}$ stimulating needle with the guidance of both ultrasound and nerve stimulator (Stimuplex, B.Braun, Melsungen AG). Ultrasound technique was performed in in-plane technique. All patients were injected the same solution named as levobupivacaine (Chirocaine, $5 \mathrm{mg} \mathrm{mL}^{-1}$; Abbott Lab/USA) $15 \mathrm{ml}$ plus isotonic $\mathrm{NaCl} 0.9 \% 5 \mathrm{ml}$ after identifying the nerves. In order to avoid intravascular injection negative aspiration was performed every $3.0-4.0 \mathrm{ml}$, during injection of the local anesthetic. The patients with inadequate block, or block failure in a nerve distribution region were excluded. One anesthesiologist that had equal experience in both ultrasound guided block and nerve stimulator technique performed all nerve blocks.

$\mathrm{HR}, \mathrm{MAP}, \mathrm{SPO}_{2}$ values were recorded before and after the block in 10 minute intervals. Demographic data, duration of block procedure, sensory and motor block onset time, duration of sensory and motor block, were also recorded by assesing sensory block by pinprick test and motor blockade using a modified Levvott rating scale from 6 (normal muscular force) to 0 (complete paralysis). Duration of block procedure was defined as the time from first skin puncture to the end of local anesthetic injection. All data were recorded by an anesthesiologist that was blinded to the study groups.

Sensory and motor block onset time was considered as the time between finishing injection of local anesthetic and to no response to the pinprick test and full paralysis. The duration of sensory block was accepted as the time between the sensory block completion and the first pain postoperatively. The duration of motor block was indicated as the time between the full paralysis and recovery of motor functions. Pain levels at postoperative period were assessed using a $10 \mathrm{~cm}$ visual analog scale (VAS) from 0 (no pain) to 10 (severe pain). Satisfaction scores of patients and surgeons were also recorded after the operation using a 5 point scale from 1 (very bad) to 5 (excellent). The surgeons also were blinded to the study groups. Hypotension, hypoxemia, bradycardia, nausea and vomiting were also recorded if occurred. In case of hypotension, hypoxemia and bradycardia, it was planned to perform ephedrine $10 \mathrm{mg} \mathrm{IV}, \mathrm{O}_{2} 4-51 \mathrm{hr}^{-1}$ with face mask and atropine $1 \mathrm{mg}$ IV respectively. If a VAS value was above 5 , the patient was administered diclofenac $75 \mathrm{mg}$ intramuscular. 
We performed a pilot study of 15 patients (5 in each group) before our main study, and calculated that a sample size of 30 patients in each group would be sufficient at an assumed $20 \%$ difference in duration of block procedure. Statistical power was calculated to be 0.82 as $\alpha=0.05, \beta=0.18$. Statistical analysis was performed with SPSS (Ver. 15.0). The data of age, height, weight, surgery time, onset time, and duration of sensory and motor block was evaluated by the Kolmogorov-Smirnov test. Age, height, weight, surgery time, onset time, and duration of sensory and motor block were compared between the groups by ANOVA test and reported as mean \pm SD. The sex and ASA physical status were compared with Chi-square test. $\mathrm{P}<0.05$ was considered significant.

\section{RESULTS}

Three patients from group $\mathrm{N}(\mathrm{n}=27)$, one patient from group E $(n=29)$ and one from group NS $(n=29)$ were excluded from the study because of inadequate block. A total of 85 patients completed the study. Demographic and operation characteristics demonstrated no significant differences between groups (Table 1).

Table I. Demographic and operation characteristics

\begin{tabular}{llll}
\hline & $\begin{array}{l}\text { Group N } \\
(\mathrm{n}=27)\end{array}$ & $\begin{array}{l}\text { Group E } \\
(\mathrm{n}=29)\end{array}$ & $\begin{array}{l}\text { Group NS } \\
(\mathrm{n}=29)\end{array}$ \\
\hline Age (years) & $38.7 \pm 11.6$ & $38.4 \pm 15.4$ & $38.0 \pm 13.7$ \\
Gender (male/female) & $9 / 20$ & $9 / 18$ & $8 / 21$ \\
Height $(\mathrm{cm})$ & $170.4 \pm 7.7$ & $167.7 \pm 6.7$ & $167.5 \pm 7.4$ \\
Weight $(\mathrm{kg})$ & $74.8 \pm 14.8$ & $72.1 \pm 11.5$ & $71.8 \pm 12.2$ \\
Operation time (min) & $66.2 \pm 7.4$ & $68.7 \pm 12.5$ & $67.9 \pm 11.5$ \\
\hline
\end{tabular}

Data are mean $\pm S D$, $n$.

No differences were found about intraoperative and postoperative MAP, $\mathrm{HR}$ and $\mathrm{SpO}_{2}$ data.

Duration of block procedure values were found similar in group E and group NS and significantly lower than in group $\mathrm{N}(\mathrm{p}<0.05)$. Sensory and motor block onset time values were found higher in group $\mathrm{E}$ and group $\mathrm{N}$, besides significantly higher in group $\mathrm{N}$ than in group $E(p<0.05)$. Sensory and motor block durations, were found higher in group $\mathrm{E}$ and group NS than in group $\mathrm{N}(\mathrm{p}<0.05)$ (Table 2). Postoperative VAS value of $12^{\text {th }} \mathrm{hr}$ was similar in all groups (Table 2). Total need for analgesics and time to first analgesic use were similar in all groups. Number of patients that needed additional analgesic in postoperative 12 hours was similar in all groups.

Patient and surgeon satisfaction scores were higher in group $\mathrm{E}$ and group NS $(\mathrm{p}<0.05)$ (Table 3$)$.
No side effects were seen in any patients.

None of the patients had the hypotension, bradycardia or a hypoxemia episode which required treatment during neither intraoperative nor postoperative period.

Table 2. Sensory and motor block characteristics and VAS score

\begin{tabular}{|c|c|c|c|c|}
\hline & $\begin{array}{l}\text { Group N } \\
(n=27)\end{array}$ & $\begin{array}{l}\text { Group E } \\
(\mathrm{n}=29)\end{array}$ & $\begin{array}{l}\text { Group NS } \\
(\mathrm{n}=29)\end{array}$ & P \\
\hline $\begin{array}{l}\text { Duration of block pro- } \\
\text { cedure (min) }\end{array}$ & $8.1 \pm 1.4^{*}$ & $4.8 \pm 1.2$ & $5.0 \pm 1.4$ & 0.000 \\
\hline $\begin{array}{l}\text { Sensory block onset time } \\
\text { (min) }\end{array}$ & $11.0 \pm 1.5^{\star}$ & $8.3 \pm 1.0$ & $6.4 \pm 1.1^{\#}$ & 0.000 \\
\hline $\begin{array}{l}\text { Motor block onset time } \\
\text { (min) }\end{array}$ & $14.7 \pm 1.4^{*}$ & $11.4 \pm 0.9$ & $8.2 \pm 1.0^{\#}$ & 0.000 \\
\hline $\begin{array}{l}\text { Duration of sensory block } \\
\text { (min) }\end{array}$ & $460.7 \pm 38.9^{*}$ & $547.7 \pm 31.6$ & $542.4 \pm 40.2$ & 0.000 \\
\hline $\begin{array}{l}\text { Duration of motor block } \\
\text { (min) }\end{array}$ & $357.9 \pm 30.5^{*}$ & $452.1 \pm 45.1$ & $461.4 \pm 36.4$ & 0.000 \\
\hline $\begin{array}{l}\text { Time to first analgesic } \\
\text { (min) }\end{array}$ & $492.5 \pm 55.9$ & $529.3 \pm 53.2$ & $533.1 \pm 51.6$ & 0.111 \\
\hline $\begin{array}{l}\text { VAS score at postop } 12^{\text {th }} \\
\mathrm{hr}\end{array}$ & $2.4 \pm 1.6$ & $2.1 \pm 1.7$ & $2.1 \pm 1.5$ & 0.759 \\
\hline
\end{tabular}

Table 3. Patient and surgeon satisfaction scores

\begin{tabular}{|c|c|c|c|c|}
\hline & $\begin{array}{l}\text { Group } N \\
(\mathrm{n}=27)\end{array}$ & $\begin{array}{l}\text { Group E } \\
(n=29)\end{array}$ & $\begin{array}{l}\text { Group NS } \\
(\mathrm{n}=29)\end{array}$ & P \\
\hline $\begin{array}{l}\text { Patient satisfaction } \\
\text { score }\end{array}$ & $2.6 \pm 0.8^{*}$ & $4.5 \pm 0.6$ & $4.3 \pm 0.6$ & 0.000 \\
\hline $\begin{array}{l}\text { Surgeon satisfaction } \\
\text { score }\end{array}$ & $1.5 \pm 0.6^{*}$ & $4.3 \pm 0.6$ & $4.4 \pm 0.7$ & 0.000 \\
\hline
\end{tabular}

\section{DISCUSSION}

Our study demonstrates that echogenic needles and nerve stimulator assisted non-echogenic needles have shorter block performing times, shorter sensory and motor block onset times and a longer sensory and motor block duration when compared to non-echogenic needles in ultrasound guided axillary brachial plexus block. We also found a higher patient and surgeon satisfaction score for the same needles.

Peripheral nerve blocks have been performed with the help of nerve stimulators before the introduction of ultrasound guidance in regional anesthesia practice (1). Peripheral nerve stimulation technique has been called blind method because it does not visualize the nerves and needle (3). Inspite of this it 
has been performed successfully by using nerve stimulators $(2,7,8)$. Ultrasound guidance in regional anesthesia made nerves visible and improved peripheral nerve block success and safety $(5,9)$. Ultrasound assistance may be used with nerve stimulation to expedite onset of axillary brachial plexus block (9). In a recent animal study of Vassiliou et al. (10) it was concluded that dual use of ultrasound and nerve stimulation together provides a higher rate of close needle-to-nerve placement and a lower incidence of hematoma. This study was performed using non-echogenic needles with the assistance of both ultrasound and nerve stimulation. Salem et al. (11) indicated in their study that ultrasound assistance to nerve stimulation had no advantages if it was performed by experienced users, further is the nerve stimulation technique also an important technique for trainees' first learning.

In time, as the anesthetists gained experience and as the technology improved both the areas of ultrasound and needle visibility, they began to use ultrasound solely for nerve blocks. There are some studies comparing nerve stimulation and ultrasound technique in peripheral nerve blocks and different results were found. In the study of Casati et al. (12), similar success rates for both techniques were indicated in axillary block. In a study by Chan et al. (13), it was concluded that ultrasound guidance significantly improves the success rate of axillary blocks. Liu et al. (14) concluded that ultrasound guidance for interscalene block does not offer major advantages over nerve stimulator guidance. Danelli et al. (15) compared ultrasound and nerve stimulation techniques and found in their recent study that success rate and onset times of block were similar, although ultrasound guidance provided shorter procedural times, fewer needle and vascular punctures. In a study at 2012, Maalouf et al. (16) compared nerve stimulator versus ultrasound guidance for placement of popliteal catheters and found similar pain scores, procedure times and analgesic consumption but less local anesthetic doses with ultrasound guidance. In our study, we used ultrasound in all groups and compared different needles and nerve stimulator addition to non-echogenic needle. We conclude that ultrasound guidance improved the results in our study. Besides, we indicate that nerve stimulation may improve the block quality of ultrasound guided axillary block when using non-echogenic needles.

Schafhalter-Zoppoth et al. (17) indicated that the anesthetist's skill in using and placing the ultrasound probe and needle is probably the most important variable influencing needle visibility. In our study all blocks were performed by the same experienced anesthetist, in order to gain most reliable results.

Needle visualization has been improving with the echogenic needles. In a review article of Hocking et al. (18) it was concluded that a good echogenic needle should increase efficacy, safety and simplicity. In a recent study, Guo et al. (19) compared different echogenic needles with non-echogenic needles in cadaver model and found echogenic needles more visible than non-echogenic needles. Hebard et al. (20) also compared three different echogenic needles with non-echogenic needles and found no significant differences in overall visibility of the needle at different insertion angles. The Sonoplex needle showed statistically higher scores of confidence and visibility at perpendicular angles. No significant differences were observed between the remaining echogenic designs and the non-echogenic control. In our study, visibility of needles was not evaluated. We compared echogenic, non-echogenic needles and nerve stimulator assisted non-echogenic needles using sensory and motor block quality and additional pain scores.

In conclusion, the outcomes of ultrasound guided axillary block with echogenic needles and nerve stimulation assisted ultrasound with non-echogenic needles are similar and better than solely non-echogenic needles. We assume that nerve stimulation assisted non-echogenic needles are as effective as echogenic needles in ultrasound guided axillary block.

\section{Competing Interests}

The authors have declared that no competing interest exists.

\section{References}

1. Ganta R, Cajee RA, Henthorn RW. Use of transcutaneous nerve stimulation to assist interscalene block. Anesth Analg, 1993; 76: 914-915.

2. Coskun D, Mahli A. The extent of blockade following axillary, supraclavicular, and interscalene approaches of brachial plexus block. Turk J Med Sci. 2011; 41: 623-631.

3. Klaastad O, Sauter AR, Dodgson MS. Brachial plexus block with or without ultrasound guidance. Curr Opin Anaesthesiol. 2009; 22: 655-660.

4. Urmey WF, Grossi P. Percutaneous electrode guidance: noninvasive technique for prelocation of peripheral nerves to facilitate peripheral plexus of nerve block. Reg Anesth Pain Med, 2002; 27: 261-267.

5. Marhofer P, Greher M, Kapral S. Ultrasound guidance in regional anaesthesia. Br J Anaesth 2004; 26: 26.

6. Marhofer P, Chan VW. Ultrasound-guided regional anesthesia: current concepts and future trends. Anesth Analg, 2007; 104: 1265-1269.

7. Cevik H, Mahli A, Coskun D. The effects of axillary block using the multiple injection method with ropivacaine in uremic and nonuremic patients. Turk J Med Sci. 2012; 42: 457-464.

8. Yurtlu BS, Hanci V, Ege A, Bostankolu SE, Ayoglu G, Ozkocak Turan I Tramadol as an adjunct for levobupivacaine in axillary plexus blockade: a prospective, randomized, double-blind study. Turk J Med Sci. 2012; 42: 55-62

9. Shrestha BR. Nerve stimulation under ultrasound guidance expedites onset of axillary brachial plexus block. J Nepal Health Res Counc. 2011; 9: 145-149.

10. Vassiliou T, Eider J, Nimphius W, Wiesmann T, de Andres J, Müller HH, Wulf $H$, Steinfeldt T. Dual guidance improves needle tip placement for 
peripheral nerve blocks in a porcine model. Acta Anaesthesiol Scand. 2012; 56: 1156-1162.

11. Salem MH, Winckelmann J, Geiger P, Mehrkens HH, Salem KH. Electrostimulation with or without ultrasound-guidance in interscalene brachial plexus block for shoulder surgery. J Anesth. 2012; 26: 610-613.

12. Casati A, Danelli G, Baciarello M, Corradi M, Leone S, Di Cianni S, Fanelli G. A prospective, randomized comparison between ultrasound and nerve stimulation guidance for multiple injection axillary brachial plexus block. Anesthesiology 2007; 106: 992-999.

13. Chan VW, Perlas A, McCartney CJ, Brull R, Xu D, Abbas S. Ultrasound guidance improves success rate of axillary brachial plexus block. Can J Anesth 2007; 54: 176-182.

14. Liu SS, Zayas VM, Gordon MA, Beathe JC, Maalouf DB, Paroli L, Liguori GA, Ortiz J, Buschiazzo V, Ngeow J, Shetty T, Ya Deau JT. A prospective, randomized, controlled trial comparing ultrasound versus nerve stimulator guidance for interscalene block for ambulatory shoulder surgery for postoperative neurological symptoms. Anesth Analg. 2009; 109: 265-271.

15. Danelli G, Bonarelli S, Tognú A, Ghisi D, Fanelli A, Biondini S, Moschini E, Fanelli G. Prospective randomized comparison of ultrasound-guided and neurostimulation techniques for continuous interscalene brachial plexus block in patients undergoing coracoacromial ligament repair. Br J Anaesth. 2012; 108: 1006-1010.

16. Maalouf D, Liu SS, Movahedi R, Goytizolo E, Memstoudis SG, Yadeau JT, Gordon MA, Urban M, Ma Y, Wukovits B, Marcello D, Reid S, Cook A. Nerve stimulator versus ultrasound guidance for placement of popliteal catheters for foot and ankle surgery. J Clin Anesth. 2012; 24: 44-50.

17. Schafhalter-Zoppoth I, McCulloch CE, Gray AT. Ultrasound visibility of needles used for regional nerve block: an in vitro study. Reg Anesth Pain Med. 2004; 29: 480-488.

18. Hocking G, Mitchell $\mathrm{CH}$. Optimizing the safety and practice of ultrasound-guided regional anesthesia: the role of echogenic technology. Curr Opin Anaesthesiol. 2012; 25: 603-609.

19. Guo S, Schwab A, McLeod G, Corner G, Cochran S, Eisma R, Soames R. Echogenic regional anaesthesia needles: a comparison study in Thiel cadavers. Ultrasound Med Biol. 2012; 38: 702-707.

20. Hebard S, Hocking G, Murray K. Two-dimensional mapping to assess direction and magnitude of needle tip error in ultrasound-guided regional anaesthesia. Anaesth Intensive Care. 2011; 39: 1076-1081. 